\section{ON THE CAUSES AND TREATMENT OF} CHOREA.

By Williax Syith, Esq., Surgeon, Bristol, Fellow of the Royal Medical and Chirurgical Society of London.

Chores is a disease frequently presenting itself to the medical man, and sometimes exceedingly obstinate and unyielding in its relations to curative measures; but in this country it rarely terminates fatally. Our treatment here is to some extent empirical, but yet, if examined upon the slender knowledge which we possess of the efficient causes of its singular symptoms, we must allow that it is highly rational. Chorea seems to be generally co-existent with an extremely irritable state of the nervous system. It most frequently occurs in children verging on puberty, and in whom the sensorial development bears an undue relation to the glandular organization. We shall be better enabled to examine the subject if we consider the temperament or habit which should be found in childhood, and the artificial condition which civilization has unfortunately too frequently produced. It may be observed, that a certain temperament, in the widest sense of the word, can be assigned to each epoch of life. On the Continent, especially in Paris, death sometimes occurs in chorea, and the state of the brain, revealed by the post-mortem examinations, quite bears me out in the view of the disease which my prior observations induced me to take. In fact, $I$ consider the disease as one of increased nervous action, deriving its source directly from too much stimulation of the nervous system and brain especially, or indirectly, from want of that normal excitement which should be found in the glandular and secerning apparatus in childhood. And this leads me to make a few remarks on the peculiar temperament of children, and on the gross deviations from it, the result of a mistaken education, which frequently occasion this and many other more fatal diseases. In infancy and childhood, the lymphatic temperament may be said to predominate. The complexion, even in those who have been exposed to atmospheric infuence, is less tinted than at any other period of life. The eyes and hair are, during this period of life, of a lighter colour. The glandular system is largely developed, in proportion to other parts of the frame. Growth and nutrition are the chief cares of provident nature in this season of life. The pursuit of trifles, where even disappointment brings but momentary regret, feelings of little intensity, passions of but shallow depth, these fill up the measure of the thinking and feeling being of infancy and childhood. This mental and moral quietude, unvexed by thoughts save those which arise in the pursuit of innocent pleasures, and unnannoyed by the painful pangs of after-life, leaves to the mere vegetative and animal existence a broad field for development, and time and opportunity for the creation of form and beauty.

These facts lead us to some important practical considerations. Thus, to attempt either by violent bodily or mental exertion to rapidly develop the physical or mental functions is very injudicious; for the nutritive and visceral activity, if circumscribed and arrested by the forced development of the locomotive apparatus, and of the brain and nervous system, must suffer. It leads to debility, atrophy, and disease; and hence, in infancy and childhood are often laid the foundations, not merely of chorea, but of prolonged and severe diseases. Do we not every day witness the most distressing instances of the worse than foolish attempts, on the part of parents, to develop the minds of their children at a premature age? If a spark of wit flash from the lips of the precocious infant, it perceives that its parents are in ecstasies of joy, and they are not slow in rewarding its proficiency. If reasoning, worthy the acuteness of a sophist, gladden the ears of the father, the ill-reasoned "sharpness" of the child meets with a reward, instead of a check. If the memory be rendered vastly retentive, by adding line on line, and date on date, the delighted friends glory in the imagined future, when the mental stores of their offspring shall have rendered him illustrious. Alas! that future rarely ever comes. A literary gladiator and practised debater, before infancy is over-or perhaps already "crammed" with sufficient chronology, arithmetic, and "useful knowledge," for two much older heads-the child has forgotten that it is such, and all the innocent pleasures of this epoch of existence are merged in a spirit of rivalry and emulation. With this forced development of the intellect, the passions endeavour to keep pace, and all the pangs and cares of manhood crowd on the monstrous abortion.

The parents see, at length, the feeble limb, the hectic cheek, the disordered stomach, and the irritable temper of the young hypochondriac. They conceive that their child is like all other geniuses, "an original," but still, this will not account for the positive ill-health. The proper treatment now would be to let the unhappy creature rest, to endeavour to check the determination of blood to the head and nervous system which your education has produced, and again to restore to the nutritive system the tone and vigour it has lost. Symptoms of chorea may come on, but rational treatment will soon overcome them. Even epilepsy or fatuity may be partially or entirely recovered from. But is rational treatment usually appealed to? No! Instead of quiet and judicious moral and therapeutic measures being employed, a new species of excitement is brought into play. The "physical education" system is called in-the calisthenic and gymnastic exercises are substituted for the catechisms of sciences and the grammars of languages. The feeble limb and unresisting muscle are stretched and tortured; the poor child does not take the amount of exercise to which Nature impels it, but emulation and harsh command supply the place of that wise and kind instructress The consequences are obvious: the little vital store which the excited brain and nervous system have not pilfered from the organs of nutrition, is stolen by the inflamed and lacerated muscular tissues. The work of destruction is rendered doubly sure, and all the healthful progress of mind and body arrested. From such a system, nothing can result but a race of imbecile and irritable men and women, who will propagate, for the curse of other centuries, progenies still more feeble.

But frequently they are not allowed to linger out even this miserable existence : sometimes epileptic convulsions, but more frequently phthisis, commencing with an ill-conditioned state of the mucous membranes, particularly that of the stomach, destroy them on the threshold of life.

As a fruitful source of chorea must this system of education ever be considered. To illustrate slightly the morbid conditions of this disease, and to afford still greater proof of the excitement of the brain, which generally accompanies this disease, as well as from the important sketch of the symptoms which they contain, I shall here direct the attention of your readers to two cases of chorea terminating fatally, extracted from the Joumal für Kinderkrankheiten, of February, 1844.

"Chorea, in its worst form, is nearly always fatal, and every year, in the Parisian hospitals, young girls die of it. It commences with frightful symptoms, generally suddenly, and without appreciable cause. Of the two cases detailed below, one occurred at the Hopital Cochin, under the care of Dr. Blache, and the other was observed by Dr. Trousseau, at the Hopital Necker. Both cases were reported by the latter gentleman.

Louise I__ aged fifteen and a half years, a domestic servant, was admitted to the Hopital Cochin, on the evening of the 21st of January, 1840. She is nearly fully formed, and although small, is tolerably strong and well made. She has never suffered from any serious illness, and has been perfectly exempt from headach, or inflammatory attacks of the brain She has menstruated for one year, but only twice during that period, and the last time was on the 12th of January, and then but very sparingly. She has generally been cheerful and lively; but for the last week an alteration has been remarked in her speech, and an inaptitude for her usual employments.

On the morning of the 18th she was attacked with headach and vomiting, of the later of which she had before complained. Soon afterwards she was unable to direct her steps, and her illness being evident from the singular movements, which were continually occasioning fright and derision to other children, she was removed, on the 21st, to the hospital.

The symptoms of the disease were now fully manifest, and presented the following appearances:-Continual movements of the extremities, of the tongue, and muscles of the face; the eyelids open and shut, and the eyes are constantly revolving in the orbits; the mouth shares in the motion of the rest of the face; and she bites the sides of her lips alternately. Her answers to questions are painfully slow; the intellectual faculties are unaffected; the appetite is good; there is no soreness on the course of the spine. On both sides of the body the movements appeared with equal rapidity and irregularity; the arm, if supinated, became quickly pronated; the hand and fingers were flexed, but moved rapidly, as if playing on a stringed instrument. Ten leeches were applied to the anus, and an aperient clyster administered. The movements continued during the night, and were so violent that the bed shook. It was difficult to imagine that the patient had slept, al though she asserted that she had. During the day she felt a great lassitude, especially in the muscles of the face.

She was placed in a sulphur bath, of the temperature of $27^{\circ}$ Reaumur, (93 Falir.) After this, she was for some time 

tranquil, then the convulsive movements became more violent,
and at length complete paroxysms ensued.

On the 26 th, the following clyster was administered, and the whole body was washed in cold water: infusion of valerian, four ounces; the yolk of an egg; assafoetida, one drachm: mix. In the evening, the movements became very violent. A mixture of camphor and musk was given, but in spite of this, the symptoms increased in severity.

On the 27th, the patient slept for an hour, during which the movements ceased, yet she was highly delirious during her sleep, frequently calling to the other patients, and woke from it in a state of great excitement. She wished to eat, and after taking a few spoonfuls of food, she experienced momentary tranquillity. She is unable to drink: after many painful efforts, if she at length bring the cup to her mouth, the fluid is passed to the fauces, but no effort of deglutition sncceeds. The next morning, the poor child presented a pitiable spectacle. The whole body was bruised and excoriated, from the continual motions. She uttered screams indicative of great suffering, although she did not complain of pain, but of general lassitude and weariness; she spoke of a choking sensation, but could now drink, which she did with avidity. She was placed in a bath of the temperature of $24^{\circ}$ Reaumur, $\left(86^{\circ}\right.$ Fahr.,) and then the cold affusion was again used; this being the third time it had been employed. A transient amendment was observed after each time. After putting her in a strait waistcoat, to avoid, if we could, any further selfinflicted injuries, she was placed back in bed. No relief was experienced. Five hours afterwards, without giving her any notice, she was plunged into a cold bath, lifted out, and again plunged six times consecutively; but in spite of this active treatment no permanent benefit was observed. An hour afterwards, twenty leeches were applied to the inner part of the thigh; as soon as these began to suck, she became more tranquil, and enjoyed some sleep during the night.

On the 28 th, a marked improvement manifested itself. In the evening, a douche of three buckets of cold water was employed, after which she became tranquil. The improvement lasted during the $29 \mathrm{th}$, on which the douche was repeated. This state of quiet continued, and the patient only complained of a sore throat.

On the 30th, the same treatment was continued, with the same favourable results. The following mixture was also ordered to be taken:-Tartrate of antimony, four grains; camphor emulsion, six ounces: mix, and take a table-spoonful every hour. The tranquil condition continued during the evening, the patient stating that she was quite comfortable.

Some anomalous movements were again observed on the 31st, together wtth great soreness of the throat, hoarseness, and stiffiness of the muscles of the neck.

February 1st, she became somewhat feverish; the pulse low.

On the 3rd, the movements recommenced in all their severity, and during the bath, became so powerful as to render it necessary to hold her. Her night was passed in a very restless condition, with some delirium. Sixteen leeches were applied to the thigh: these drew a large quantity of blood, without any visible amelioration in the symptoms. During the next night she screamed loudly. A draught, containing two grains of tartarized antimony, was given her, which produced copious vomiting, and evacuations by stool.

On the 8th, the movements again attacked the face and eyes. A draught, containing four grains of tartrate of antimony, was given. She vomited twice, but no purging ensued.

On the 10 th, the symptoms increased in a very alarming manner. During the night, the fever became very marked; in the morning she sobbed and cried, but this could not be considered as indicative of pain, as none seemed to be present. During the day, she took four pills of extract of belladonna, each containing the fifth of a grain. The symptoms, however, increased in severity, and the grinding of the teeth, with the convulsive movements of the cheeks and lips,produced literally foaming at the mouth. In the evening, a draught containing half a grain of musk was given her.

On the morning of the 11th, she was more tranquil; the features, however, had a sumken and contracted appearance; the irritation increased during the day; the features became much distorted, and the sereams were fearful; this excited condition lasted during the whole night; the intelligence is not, however, affected.

On the 12th, perfect prostration was evidently commenced; the countenance was livid and distorted; the eyes fixed; some marked movements are still observed in the face and hands : there is a loud râle in the trachea, and a sub-crepitant rhonchus heard at the lower part of the chest; the lungs are eridently congested; the pulse is tolerably quick, but yet not depressed; the skin is still warm; the sensorium is unaffected; she answers rationally; the tongue is moist, and deglutition easily performed; complains much of thirst. A large blister was applied to the chest, and sinapisms to the legs. A draught containing two grains of kermes mineral was given. The excitement produced by these means recalled for a short time the departing powers of life, but without permanent good effect, as she died in the middle of the day.

Post-mortem examination-Cranium: the membranes are highly injected, and are adherent to the cerebral surface in their whole extent; the veins of the pia mater are distended with dark-coloured blood; there is a distinct effusion of blood on the pons Varolii ; no portion of the brain was ulcerated or absorbed, notwithstanding the complete adhesion of the pia mater; the convolutions are rather flattened, and a red tint is observable in the cortical substance, which increased on the access of air. Not the slightest alteration could be perceived in the medulla spinalis or its membranes, although examined with the greatest care.-Thorax: the inferior portion of the left lung is the seat of undoubted congestion ; in one very circumscribed spot, pneumonia, in the first stage, is perceptible.-Organs of generation: the hymen is present; the os uteri is of a whitish colour; the posterior surface of the aperture of a reddish-brown hue; the cellular tissue of the body of the uterus is hyperæmial, and in places reddened with infiltrated blood; the left ovarium exhibits the mark of a slight ulceration on its outer surface; internally, the Graafian vesicles lie at various depths, one lying very near the surface. The stomach and viscera do not appear to have been examined-an omission much to be lamented.

Case 2.-Maria $\mathrm{M} \longrightarrow$ - aged sixteen years, has menstruated since her fourteenth year; has felt herself unwell for the last eight months from the suppression of the menses, in consequence of a cold which she caught at that period. In December, 1842, without any other previous illness, she was attacked with irregularity of articulation, and rapid spasmodic movement of the lower jaw. In the same manner the whole of the left side began to be affected with chorea, the movements being particularly observable in the fingers and toes. Eight days subsequently the right side was attacked, although with less severity; the hearing became obstructed, especially on the left side; double vision occurred, and the left eye became very weak; she speaks with difficulty; the sensorium is unaffected; she halts with the left side to a great extent. The left leg seems, in fact, quite unable to support its share of the weight.

Treatment.-A bath; three pills to be taken during the day, each containing one sixth of a grain of strychnine.

January 12th.-For three days the patient has taken the half of a grain of strychnine in the three pills, without any other effect than a slight numbness in the lame side, and a little diarrhœa. This day she took two-thirds of a grain in each pill, and, after the second dose, she was seized with tetanic spasm, which lasted an hour, and during which she suffered great pain. The next morning the abnormal movements were lessened, and on the left side scarcely any could be perceived. At the same time, neither the sight nor the movements of the jaw have returned to a healthy condition, and the hesitation in the speech continues. The former quantity of strychnine was ordered in the three pills. By the middle of the day the chorea had so improved, that when I stood at the bed-side of the patient I could perceive no movements. It is worthy of remark, that the double vision totally disappeared immediately after the tetanic symptoms occurred, although the rolling of the eyes, and the movements of the eyelids, continued till this morning.

18th.-All the natural functions are performed without disturbance; the movements have ceased entirely. The strychnine was now discontinued.

The result of our treatment up to this period was as remarkable as it was satistactory. In a few days, one of the severest cases of chorea had ceded to the action of the strychnine. The disease had, in fact, totally disappeared, and we were far from anticipating the melancholy career which it had yet to rum.

On the 21st, I found our little patient again tossing to and fro with the peculiar movements of chorea. It had recommenced with a fright caused by the death of a woman in the adjoining bed. This had occurred the day before. During the night, the excitement had considerably subsided. Strychnine was again employed, and the chorea disappeared even more easily and quickly than on the former occasion. All went on well till the 25 th, when the patient received a very distress- 
ing letter from some friends. A more marked attack supervened than either of the previous ones. For the four following days the movements continued, and the strychnine seemed to have lost its controlling powers. I therefore considered it best to suspend its employment, a determination which I have since regretted. I ought to have persevered with it, after witnessing the favourable results which had twice followed its employment. As opium, however, had in many cases done essential service, I no longer hesitated to give it a trial. I commenced by ordering three grains of the sulphate of morphia in two ounces of simple syrup; about half a tea-spoonful to be frequently taken, till tranquillity and sleep should have ensued. On the third day we found that the excitement had increased, and not a moment of rest or sleep had been obtained. Six grains of the sulphate of morphia were now ordered in the two-ounce mixture, and as no improvement was manifested at the third dose, the quantity was increased to ten grains. On the fourth day, the motions were still more alarming. The skin of the elbows and arms is excoriated. Other parts of the body, from being dragged hither and thither on the bed, are much reddened. Meanwhile, the morphia has procured two hours' sleep, during which, however, the movements continued without the slightest improvement. Encouraged, however, by the appearance of the sleep, I increased the narcotic salt to one scruple, yet, in the course of the day, the movements augmented to a fearful extent; the arms much swollen, bleeding, and bruised, and looking as if attacked with phlegmonous erysipelas. She dashes her limbs against the bed-posts with tremendous force; the body suddenly arches backwards, so as to form a convexity in front, exhibiting that form which in tetanus would be denominated "opisthotonos;" but this condition is only transient, and the very reverse, or "emprosthotonos," takes place. The head is incessantly rolled from one side to the other. If anything be given her to drink, she endeavours to seize it, being very thirsty, but she has lost all power of directing it to her mouth, and strikes with her forehead, nose, eyes, or lips against the ressel which is offered to her. Her tongue is bruised and lacerated by frequent bites with her teeth.

A sulphur bath was ordered, with subsequent cold affusion, and the dose of morphia to be increased. It required the strength of four strong individuals to hold her in the bath, and they did it with difficulty.

After the bath, the patient slept for a short time; but immediately afterwards the excitement became worse than ever. The skin, throughout its entire extent, is excoriated and red. The incessant movements, in a single day, completely destroyed a bed-covering of very strong linen. As the convulsive movements continued with the same intensity on the following day, and as life could not long endure such suffering, I changed the opium for antispasmodics. In the evening, a restless sleep commenced, which was followed by great nervous excitement and delirium. 'The patient imagined that she was oppressed by some heavy load, and frequently called out, "I am suffocating!"

A loud râle was now audible over the whole chest; the face was pale; the skin hot; the pulse full, and of moderate frequency. Soon afterwards, she fell into a deep coma, and died the next morning.

Upon examination, there was found great excoriation of the skin, and infiltration of blood into the sub-cutaneous cellular tissue. There were sloughs on the left ankle and right elbow. In the brain, there was a slight congestion of the vessels of the pia mater, with distention of the sinuses. No fluid in the ventricles; the membranes are healthy; and after a minute examination of all parts of the brain, no other morbid appearances call be discovered. Nothing abnormal could be discovered in the spinal cord or its membranes. There is a slight congestion of the posterior portion of the lungs, and a quantity of mucus in the bronchial tubes."

In a case which not loug since fell under my observation, the patient was a little girl, aged seven years, of extreme in tellectual powers for one of such tender years. Her replies to my questions were so remarkably sharp as completely to astonish me. The bowels were inactive; the tongue flabby and pale; she suffered firom slight headach; the forehead was extremely prominent; it was feverishly hot. The treatment in this case consisted in the employment of gentle purgatives, - of sulphate of zinc in small doses, both from its stimulating effect on the mucous membrane, and from its general tonic character-a very useful drug in this disease; of cold water, especially applied to the head, from which, also, blood, in very small quantities, was sometimes subtracted by a leech or two. The patient speedily recovered.
Treatment.-The treatment, therefore, in this complaint, must be directed to the following points:-

1st.-Mental and moral quietude. All attempts to excite the intellect or feelings to be avoided. The extreme excitement about the brain to be subdued by occasional slight local depletion,- by the âpplication of cold water, and by keeping the hair short.

2ndly.-The normal activity of the intestines and stomach to be restored, first, by an emetic of sulphate of zinc, to be followed by the employment of brisk purgatives of castor oil, and oil of turpentine; subsequently, small doses of sulphate or oxide of zinc.

3rdly.-General tonic measures. Amongst these, cold water holds the highest place. It should not, however, be applied so as to give a violent shock to the nervous system; but applied either with a sponge or gentle shower-bath.

4thly.-All measures which would have a tendency to congest the brain are to be avoided. Hence, $\mathrm{I}$ would not advise opium, except in cases where all tendency to congestion of the brain, or its membranes, is clearly absent. Even in these cases, camphor, in grain doses, may be advantageously substituted.

As before observed, cold water must not be employed in the terrifying and violent manner which was evidently its mode of employment in the cases translated from the foreign journal. All its beneficial effects may be obtained by a gentle shower bath; or if this cannot be borne, by sponging, or friction, for five minutes, in a wet sheet. Warm-water pediluvia. must not be neglected, as the state of the feet bears an important relation to the condition of the brain. The exercise should be such as nature prompts, and that only. No "plyysical education" quack should be permitted to rack the feeble muscular fibres; and above all should be observed the golden maxim of the great Latin physician, that the exercise should be "citra fatigationem."

As a general rule, spirits, beer, and wine, from obvious reasons, should be avoided. In one case which I attended, I found the mother gave the patient, a very young child, strong beer, and spirits and water, "to brace the nerves," as she expressed it. This, of course, augments the cerebral excitement to a great extent. Sometimes, however, a little ale may be given with advantage. Strychnine may, when used with great caution, produce beneficial results; but when other means will succeed, we are not justified in the employment of such a powerful poison.

Additional remark.-I would beg to call the attention of your readers to the second case of chorea which I have translated, as to the cause of the two relapses - a fright and an unpleasant letter, both powerfully affecting the feelings. Upon some future occasion I trust to bring before their notice a sketch of a peculiar temperament, the "neurotic" and its great connexion as a predisposing cause of this and other diseases of the nervous system.

Bristol, January, 1846

\section{REPORTS OF CASES OF DISEASE OF THE HEART AND OF ANEURISM.}

By Samuel Fenwrck, Esq., Surgeon, North Shields, Lecturer on Anatomy and Physiology at the Newcastle-upon-Tyne School of Medicine and Surgery.

TCBERCUlous DISEASE OF THE HEART.

CASE 1.-A man, aged 45, suffered from symptoms of typhus fever. When I saw him, nine months afterwards, his appearance was strongly indicative of phthisis. He complained of cough, with copious expectoration, oedema of the legs, and great emaciation, which had affected him ever since his recovery from the fever. The pulse was frequent and feeble, and he had once spit blood. The chest was, from accidental circumstances, but hastily examined. The sound, on percussion, was much duller on the left anterior chest than on the right at its upper part. On the right anterior chest, a dull sound commenced at the fourth rib, and extended downwards to the lower edge of the liver, which was felt projecting below the costal cartilages. Posteriorly, the resonance of both sides pretty equal and natural, excepting that dulness commenced inferiorly on the right side at the same point as on the front. Mucous râles existed on both sides, excepting over the dull part of the right chest, where respiration was absent. The heart's sounds were not noticed, nor its extent ascertained by percussion. He sauk a few days after the examination.

Diagnosis.-From the general svmptoms, it was concluded that the patient was affected with phthisis, and this view was 